\title{
Cut Pumpkin Sign- A Diagnostic Radiological Sign in Pulmonary Contusion
}

\author{
Authors \\ Ravindran Chetambath ${ }^{1}$, Jabeed Parengal ${ }^{2}$, Mohammed Aslam³, \\ Sanjeev Shivashankaran ${ }^{4}$ \\ ${ }^{1}$ Professor \& Head, ${ }^{2}$ Asst. Professor, ${ }^{3,4}$ Senior Resident
}

Dept. of Pulmonary Medicine, DM Wayanad Institute of Medical Sciences, Wayanad, Kerala, India

\begin{abstract}
Pulmonary contusion (lung contusion) following blunt trauma to chest is a relatively self- limiting disease, even though it's clinical and radiological picture may mimic serious other diseases. Better understanding of the pathogenesis and radiological appearance may help in timely, appropriate intervention.
\end{abstract}

Keywords: Pulmonary contusion, Blunt trauma, Cut pumpkin.

\section{Introduction}

Pulmonary contusion is a frequent complication of blunt trauma of the chest. This occurs when chest is compressed between two hard objects or due to deceleration force when moving body hit against a hard surface. Radiological presentation may mimic many other diseases such as ARDS, pulmonary infarction and lung laceration. Here we present the pathognomonic HRCT findings of pulmonary contusion and name it as 'cut pumpkin sign' as it resemble the cut surface of a cheese pumpkin.

\section{Discussion}

Pulmonary contusion develops due to blunt injury to the chest in accidents. Pulmonary contusion is seen in $30-75 \%$ of patients with significant blunt trauma. Blunt trauma of chest occurs when chest is compressed between two hard objects or due to deceleration force when moving body hit against a hard surface. The risk of pulmonary contusion appears to correlate with severity of crash and the proximity of the site where the patient hits ${ }^{(1)}$. The possible mechanisms for contusion are the alveolar tearing or shearing at the gas-liquid interface. Interior of the lung may be affected even in the presence of intact visceral pleura due to variation in intrathoracic pressure during the impact. Pulmonary contusions generally develop over the first 24 hours and resolve in about one week $^{(2)}$.

Pulmonary contusion is often overlooked or missed during the initial evaluation because of its late presentation and also due to the other associated injuries. Clinical presentation also is misleading as it may vary from tachypnea and hypoxia to acute respiratory distress syndrome. Xray chest is not sensitive as it may be normal or show only nonspecific infiltrates. Proper radiological evaluation with HRCT after 6-24 hours of injury will give important information regarding pulmonary contusion. This is important because pulmonary contusion is self-limiting and resolve spontaneously by 3-5 days ${ }^{(3)}$. Intubation 


\section{JMSCR Vol||05||Issue||07||Page 25464-25466||July}

and mechanical ventilation can be avoided if diagnosed early and treated conservatively.

HRCT thorax shows dense non-segmental, subpleural, crescentic opacity on the side of impact and the lesion becoming less dense and nonhomogenous (ground glass opacity) towards the deeper parenchyma (Fig-1 \& Fig-2). This finding is characteristic of pulmonary contusion (4). Density and depth of the sub-pleural lesion is decided by the force of impact. The sign is named as "cut pumpkin sign" as this can be compared to the cut surface of a cheese pumpkin (Fig-3). Rarely the dense opacity may be on the opposite side of impact due to contrecoup injury. Sparing of outer 1-2 $\mathrm{mm}$ rim of subpleural portion of lung described earlier ${ }^{(4)}$ as characteristic feature is not observed in most of the adult cases.

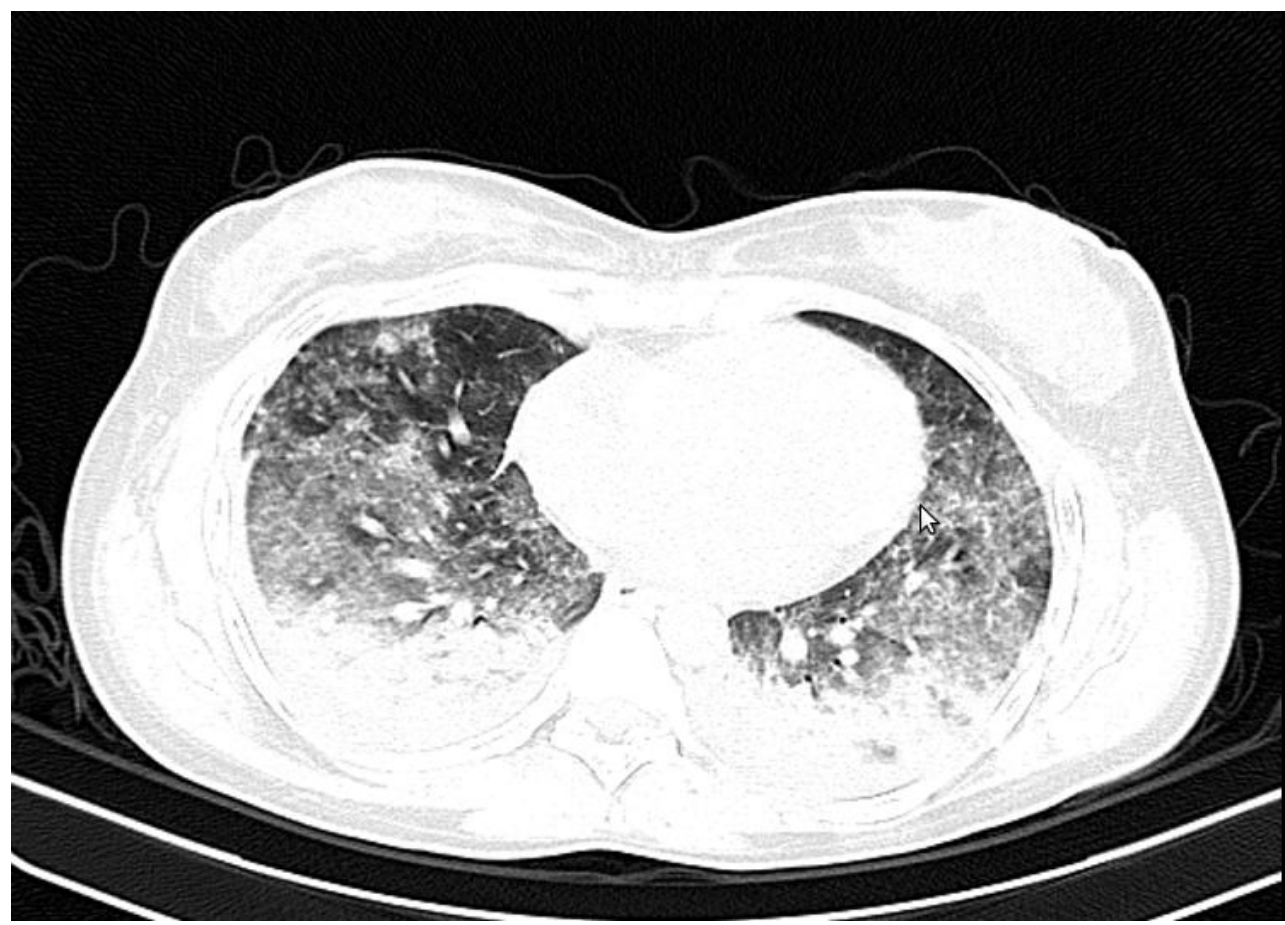

Fig-1: HRCT Thorax of a 30 year old female involved in a road traffic accident showing dense non segmental opacity with areas of ground glass shadows in deeper parenchyma.

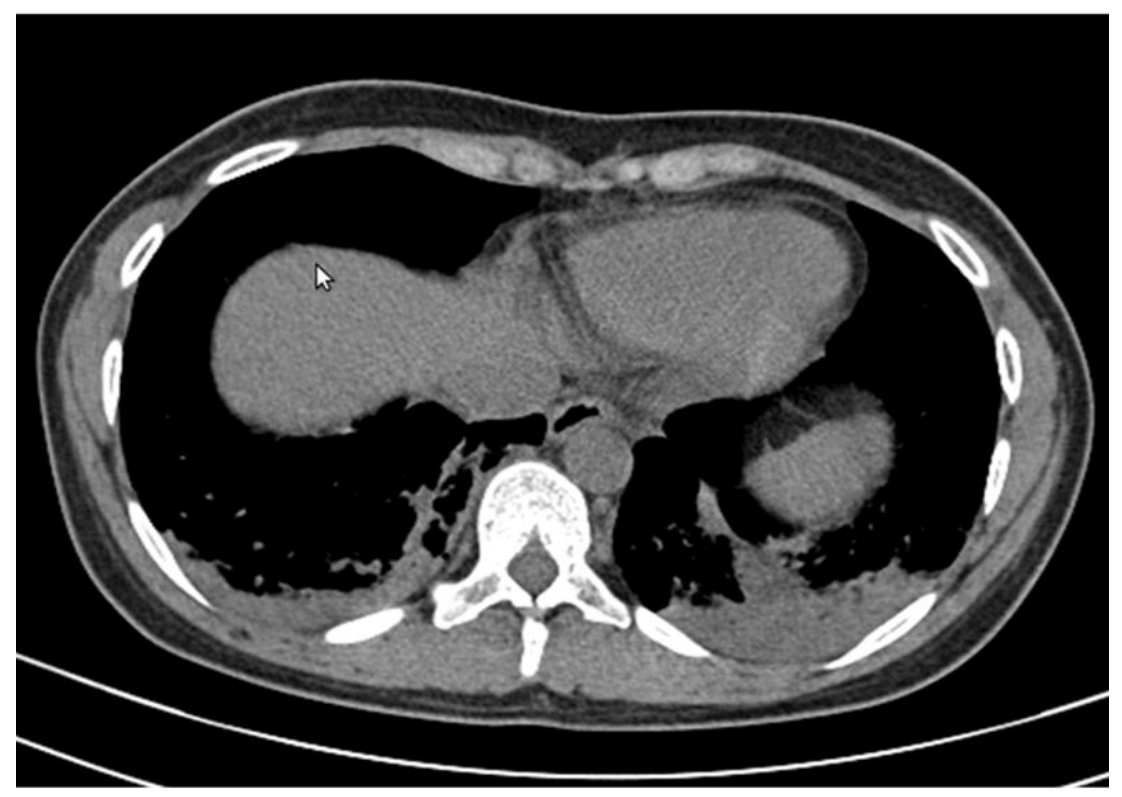

Fig-2: CT Thorax mediastinal window demonstrating the subpleural opacity. 


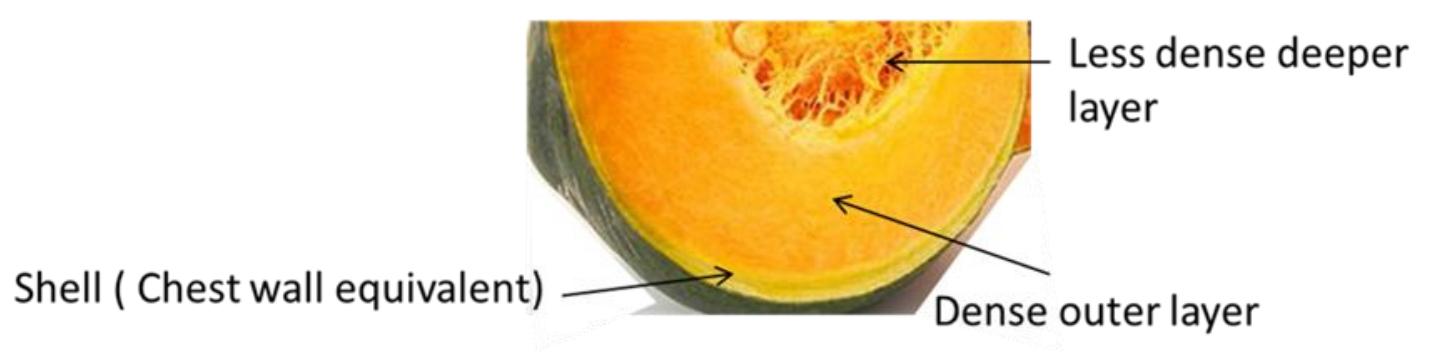

\section{Cut surface of a cheese pumpkin (Cucurbita moschata)}

Fig-3: Cut surface of cheese pumpkin

\section{Conclusion}

Lung being a target organ in most of the accidents is involved either directly or indirectly. Clinical manifestations of pulmonary contusion vary from mild injury to acute respiratory distress syndrome. Early assessment to ascertain the type and severity of injury and prompt treatment will help in complete recovery. This radiological sign will help in differentiating pulmonary contusion from other serious injuries like hematoma, laceration and pulmonary thromboembolism.

\section{References}

1. Liman ST, Kuzucu A, Tastepe AI, Ulasan GN, Topcu S. Chest injury due to blunt trauma. Eur J CardiothoracSurg 2003; 23(3):374-78.

2. O'Connor JV, Kufera JA, Kerns TJ, Stein DM, Ho S, Dischinger PC, Scalea TM. Crash and occupant predictors of pulmonary contusion. J Trauma. 2009; 66(4):1091-95.

3. Richardson JD, Adams L, Flint LM. Selective management of flail chest and pulmonary contusion. Ann Surg 1982; 196(4):481-87.

4. Kerns SR, Gay SB. CT of blunt chest trauma. AJR Am J Roentgenol. 1990; 154 (1): 55-60. AJR Am J Roentgenol (citation) - Pubmed citation. 